\title{
AVALIAÇÃO DE MANIFESTAÇÕES PATOLÓGICAS IDENTIFICADAS NAS ESTRUTURAS EM MADEIRA DO CENTRO DE EVENTOS IBC (INSTITUTO BRASILEIRO DO CAFÉ)
}

\section{Evaluation of pathological manifestations identified in timber structures of the Center of Events IBC (Brazilian Institute of Coffee)}

\author{
Juliana Furtado Arrobas Martins ${ }^{1}$, Cesar Fabiano Fioriti ${ }^{2}$
}

Recebido em 16 de fevereiro de 2016; recebido para revisão em 10 de junho de 2016; aceito em 10 de julho de 2016; disponível on-line em 10 de agosto de 2016.

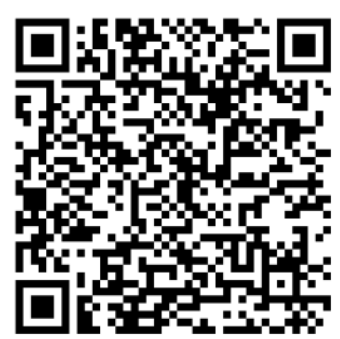

PALAVRAS CHAVE:

Manifestações

patológicas;

Deterioração;

Degradação;

Estruturas em madeira; Edificação pública.

\section{KEYWORDS:}

Pathological manifestations;

Deterioration;

Degradation;

Timber structures;

Public building.

\section{* Contato com os autores:}

1 e-mail: juarrobas@hotmail.com (J. F. A. Martins)

Graduanda em Arquitetura, Bolsista FAPESP, Universidade Estadual Paulista (UNESP).

2e-mail: fioriti@fct.unesp.br (C. F. Fioriti)

Professor Doutor do Departamento de Planejamento, Urbanismo e Ambiente da Universidade Estadual Paulista (DPUA / UNESP).
RESUMO: Este trabalho trata de um estudo de caso realizado no edifício do Centro de Eventos IBC (Instituto Brasileiro do Café), sendo este um dos mais antigos e conhecidos do município de Presidente Prudente, interior do estado de São Paulo; em que por meio de inspeção visual foram identificadas as manifestações patológicas presentes e as mais frequentes no sistema estrutural em madeira. Para isso foi realizada a análise dos aspectos gerais das anomalias, com o objetivo de identificar o tipo de dano encontrado. As manifestações patológicas detectadas que ocorreram com maior incidência foram: podridão das peças, atuação de agentes bióticos, irregularidades geométricas, uniões deficientes em cavilhas, reparos deficientes e fissuras. Por fim, são apresentadas as causas prováveis e as possíveis soluções de reparo dos problemas patológicos, onde se percebeu que a maioria dos danos poderiam ter sido minimizados caso houvesse um programa de manutenção periódica preventiva no edifício. Diante do exposto, o trabalho contribui como forma de exemplificar as possíveis manifestações patológicas que ocorrem em elementos construtivos em madeira, bem como suas causas prováveis e possíveis soluções, servindo de alerta para projetistas, construtores e usuários, a fim de que se passe a ter mais cuidado com as especificações de procedimentos, com a execução das estruturas, assim como sua utilização.

ABSTRACT: This is a case study performed in the building of the Center of Events IBC (Brazilian Institute of Coffee), being this one of the most known and old in the city of Presidente Prudente, state of São Paulo; in that by means of visual inspection were identified the pathological manifestations present and the more frequent in structural system in wood. For this reason the analysis was performed of the general aspects of anomalies, with the aim of identifying the type of damage found. The pathological manifestations detected which occurred with greater incidence were: rotting of parts, actuation of biotic agents, irregularities geometrical, unions deficient in gudgeon pins, repairs handicapped and cracks. Finally are presented the probable causes and possible solutions for repair of pathological problems, where it was noticed that most of the damage could have been minimized if there was a program of preventive periodic maintenance in the building. This work contributes for exemplify the possible pathologic manifestations that occur in building elements in wood, as well as your probable causes and possible solutions, serving as a warning for designers, builders and users, in order to have more caution with procedure specifications, structure execution, as well as your use. 


\section{INTRODUÇÃO}

A madeira é um dos mais antigos materiais de construção, juntamente com a terra crua, a pedra natural e as fibras vegetais. É um material natural com enormes potencialidades na indústria da construção e que se comporta muito bem quando aplicado em edifícios se estes forem projetados, construídos e mantidos de forma adequada.

O uso da madeira pelo homem como sistema construtor remete às origens da edificação, tanto como elemento estrutural e como acabamento. A madeira é constituída por uma estrutura tubular de condutas paralelas formadas com base na lignina e celulose, o que the confere uma reação mecânica ótima no sentido das fibras.

Engenheiros e arquitetos ao definirem projetos que utilizem a madeira como principal elemento construtivo precisam por obrigação ter conhecimentos das espécies mais apropriadas e adequadas, considerando alguns fatores como a localização do empreendimento e os agentes biológicos a qual a construção será exposta. Desta maneira, torna-se possível determinar o tipo de construção, os detalhes dos sistemas de proteção e construtivos que irão garantir a vida útil da edificação (RODRIGUES e SALES, 2013).

À medida que os avanços tecnológicos ocorrem, novas potencialidades de uso, mais sofisticadas, são inventadas para aplicação da madeira, e novas empresas vêm empregando a madeira como material estrutural. Em consequência, diversas universidades nacionais e internacionais, têm pesquisado esse nobre material para uso estrutural, difundindo uma vasta literatura, e elaborando diversas normas técnicas, principalmente no que se diz respeito, às propriedades dos materiais envolvidos, aos critérios de projeto estrutural e às práticas de execução das construções (BRITO, 2014).

Ainda segundo Brito (2014), a madeira é uma combinação de polímeros naturais que apresenta resistência e durabilidade como material estrutural. Entretanto, a partir do momento em que a árvore é formada, a madeira está susceptível a degradação por uma variedade de agentes. $O$ dano varia desde pequenas descolorações até deteriorações mais graves por ataques de insetos e/ou fungos decompositores.

Para Souza e Ripper (1998) os problemas de deterioração da estrutura e de seus materiais componentes decorrem, em grande parte, além das características físicas e químicas do material, de um projeto inadequado e de uma execução mal cuidada, deficiências que ainda se constata serem comuns, provocando a ocorrência de falhas que, fatalmente, resultam na necessidade de recuperação ou de reforço da estrutura (ou até mesmo, em casos extremos, de demolição).

No entanto, alguns fatores precisam ser mais explorados a fim de aumentar a vida útil das estruturas de madeira, tais como a inspeção e a manutenção periódica preventiva (CAMPOS, OLIVEIRA e SALES 2002; BRITO e CALIL Jr., 2013). Simplificadamente, a inspeção preventiva corresponde a vistorias periódicas e sistemáticas, para a avaliação de sinais de deterioração, tais como:

- manchas e descolorações;

- áreas úmidas, condensações;

- infiltrações, goteiras, entre outros.

Já a manutenção e os reparos têm por finalidade:

- remover sujeiras e evitar formação de acúmulos de umidade para evitar a biodeterioração;

- desentupir e limpar as calhas e sistemas de drenagens de águas;

- reparar coberturas e telhas;

- adicionar coberturas onde necessárias;

- restaurar os acabamentos protetores em tempo adequado.

Para os casos mais extremos, que requerem intervenções mais específicas de reabilitações, torna-se fundamental a pesquisa científica aprofundada de técnicas de reabilitações e/ou reforços com materiais orgânicos ou inorgânicos, principalmente tendo em vista a grande variabilidade de espécies de madeira, sejam nativas ou reflorestadas, existentes no Brasil. Geralmente, quando não há manutenções periódicas preventivas ou quando ela ocorre 
esporadicamente, as recuperações em elementos estruturais de madeira, resultam em técnicas relativamente caras, de manutenções, reabilitações, reforços ou em intervenções com substituições parciais ou totais de elementos estruturais.

Desta maneira, a maioria das manifestações patológicas poderia ser evitada se houvesse um melhor detalhamento de projeto, escolha apropriada dos materiais e correta execução da construção, assim como uma maior preocupação com a realização das intervenções de manutenção nos elementos que compõem as edificações (KLIMPEL e SANTOS, 2010).

De maneira paralela, temos o material de construção madeira que possui diversas propriedades, como por exemplo, o baixo consumo de energia para seu processamento, a alta resistência específica, as boas características de isolamento térmico e elétrico, além de ser um material muito fácil de ser trabalhado manualmente ou por máquinas (ZENID, 2002).

Segundo Cruz (2001), embora seja comum encontrar peças de madeira em serviço com maior ou menor nível de deterioração, também são igualmente fáceis de serem encontrados diversos exemplos de estruturas ou artefatos de madeira em bom estado de conservação, com centenas ou mesmo milhares de anos, em consequência de uma exposição a condições ambientais particulares que não favorecem a sua deterioração. Isto é fato porque as deteriorações em elementos de madeira surgem como resultados de ações de agentes biológicos, físicos, químicos ou mecânicos em função das condições de agressividades ambientais em que esse material fica sujeito ao longo de sua vida útil.

A madeira oferece ainda boa resistência à compressão e excelente resistência à tração, é um material flexível, pode ser cortada e moldada de várias formas, com fácil união por colagem ou embutido. Porém possui algumas desvantagens já que é um material anisotrópico, ou seja, suas propriedades mecânicas dependem da disposição de suas fibras, tem composição irregular, e é vulnerável aos agentes bióticos e abióticos causadores das anomalias (MAIDEL et al., 2009).
São diversas as manifestações patológicas que afetam as estruturas em madeira, e cada uma delas está relacionada ao fator que as originaram. Os principais causadores das anomalias em madeira são: deficiência projetual e construtiva, origem abiótica (os agentes químicos, agentes atmosféricos e o fogo) e origem biótica.

O envelhecimento precoce de muitas estruturas de madeira e a sua consequente perda de prestígio como material estrutural, ocorrem, principalmente, devido às deficiências de concepção e/ou utilização, relacionadas tanto com a fase projetual quanto com a construtiva, que acabam por acarretar em manifestações patológicas. As interferências na estrutura, posteriormente à sua construção, como por exemplo, a execução de novas aberturas, o aumento das sobrecargas de utilização, o aumento do vão entre as peças, a entrada de água líquida, a falta de manutenção, entre outros, são fenômenos que, na maioria das vezes, geram patologias (BOTELHO JUNIOR, 2006).

Diante disto, este trabalho teve como objetivo detectar, visualmente, as principais manifestações patológicas presentes e as mais frequentes no edifício que origina o Centro de Eventos IBC (antigo Instituto Brasileiro do Café), doravante denominado de IBC, situado no município de Presidente Prudente, em que por meio de inspeção visual são apresentados os aspectos gerais e as causas prováveis das anomalias identificadas no sistema estrutural do edifício. Salienta-se, contudo, que não fez parte do objetivo, entrar no mérito da qualificação e da atuação dos profissionais, assim como das empresas que participaram dos projetos e execução deste edifício, sendo o único foco a identificação das manifestações patológicas vistas sob a ótica da sintomatologia.

\section{METODOLOGIA}

$\mathrm{Na}$ apresentação de qualquer assunto do conhecimento humano, o método do estudo de caso é altamente rico sob o ponto de vista didático. Dessa forma, o estudo de caso foi a alternativa expositiva escolhida neste trabalho para apresentar 
o equacionamento das soluções dos conflitos que o envolvem.

Serão relatados os procedimentos metodológicos utilizados para o desenvolvimento do trabalho de campo e seus desdobramentos. A metodologia foi constituída de quatro etapas, em que são apresentadas esquematicamente, na Figura 1.

Conforme as etapas utilizadas no desenvolvimento deste trabalho, foi possível percorrer um caminho curto e simplificado, visto que não foram utilizadas etapas de exames adicionais e de execução das terapias, mesmo porque não foi objetivo deste trabalho realizar exames laboratoriais sobre as propriedades físicas e químicas do material constituinte do edifício. Assim: - 1a Etapa: A trajetória foi iniciada com a vistoria do local e o levantamento do histórico do edifício. A vistoria consistiu na verificação dos efeitos das anomalias existentes utilizando os sentidos da visão, do olfato, da audição e do tato. Realização de visitas in loco no edifício, com o objetivo de identificar e fotografar as manifestações patológicas existentes no sistema estrutural de madeira;

- 2a Etapa: Descrição dos aspectos gerais das manifestações patológicas encontradas no sistema estrutural do edifício objeto de estudo;

- 3a Etapa: Formulação das hipóteses de diagnósticos das causas prováveis e possíveis soluções de reparo das anomalias durante a etapa de vistoria do edifício. As formulações das hipóteses foram baseadas na semelhança dos casos encontrados com aqueles citados pelos autores referenciados neste trabalho;

- 4a Etapa: Com o diagnóstico mais provável definido, foram formuladas a análise e conclusões.

Algumas limitações foram encontradas no desenvolvimento desse trabalho, merecendo destaque as informações incompletas referentes as etapas de execução da construção do edifício, a impossibilidade de obtenção de amostras através de processo destrutivo e a inexistência de projetos complementares.

\section{RESULTADOS}

\subsection{ESCOLHA DO EDIFÍCIO IBC}

O critério de escolha do edifício objeto de estudo partiu do quesito estrutural, ou seja, a definição da madeira como material constituinte do sistema estrutural e ter suas estruturas aparentes, pois nestas condições seria possível identificar e analisar, a partir da vistoria a campo e fotografias digitais, as eventuais manifestações patológicas, bem como evidenciar as mais frequentes.

\subsection{BREVE HISTÓRICO DO EDIFÍCIO IBC}

Os desafios que o Brasil necessitava enfrentar quanto ao cultivo do café foram aparecendo à medida que essa cultura evoluía e crescia dentro do país. Doenças e pragas chegaram as safras, e, desde então, foram criados institutos de pesquisas. O primeiro deles, segundo Macedo (2013), com o encargo exclusivo de cuidar do café, surgiu por volta dos anos 1940 e foi chamado de Instituto Brasileiro do Café (IBC). A missão era definir uma política para o setor, que coordenava e controlava estratégias desde a produção até a comercialização interna e externa. Nesta época, foram construídos diversos armazéns com a espécie Peroba-rosa, em várias cidades do estado de São Paulo para estocagem do café, que perdeu o preço e necessitava de um local para ser armazenado. Em 1990, a instituição foi extinta e alguns dos galpões foram demolidos, porém, todo patrimônio do IBC foi incorporado ao Ministério do Planejamento, Orçamento e Gestão. Em 4 de abril de 2007, a prefeitura municipal de Presidente Prudente assinou um contrato de comodato que concedeu o direito de administração e serviço do edifício por 30 anos (até 2036).

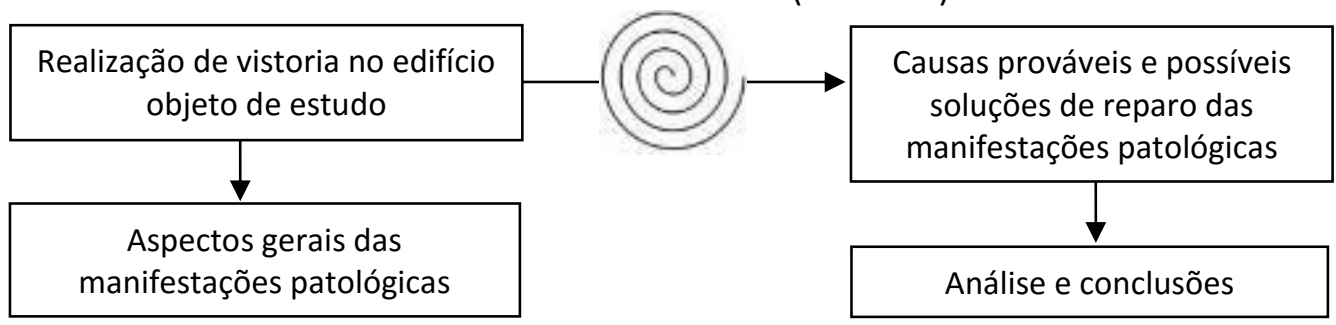

FIGURA 1: Esquema das etapas executadas no desenvolvimento do trabalho. FONTE: Autoria Própria. 
Neste período o galpão foi adaptado para receber eventos, foram construídos banheiros, novas portas, instalação de iluminação adequada e de níveis diversos de segurança (aplicação de produtos antichamas, luzes de emergência, extintores, etc.). O edifício é capaz de abrigar aproximadamente 10.000 pessoas. Atualmente, o IBC recebe feiras, shows, congressos e comemorações tradicionais do município.

\subsection{ARQUITETURA DO EDIFÍCIO IBC}

A primeira impressão que se experimenta ao deparar-se com a parte externa do edifício IBC é considerá-lo apenas como mais um barracão antigo. No entanto, ao adentrar neste edifício evidencia-se o diferencial que este possui. Sua estrutura imponente de grandes dimensões nos remete ao trabalho e sabedoria exercida pelos grandes carpinteiros da época, e sua ampla extensão nos remete a uma catedral gótica, relacionando a imponência do espaço sobre o usuário, assim como com sua estrutura, que direciona o olhar para cima no sentido das aberturas de ventilação e iluminação.

O IBC possui planta livre, podendo ser contemplado em toda sua extensão. O espaço possui uma arquitetura predominante inglesa, a qual expõe as técnicas construtivas mais simples, baseadas nos materiais disponíveis e de fácil acesso do período. Nota-se uma arquitetura de caráter "artesanal", na qual os artesãos eram os carpinteiros que desenvolveram muito bem as técnicas de samblagem (ato de criar junções e encaixes na marcenaria).
A leveza, progressiva com o aumento de altura, pode ser relacionada à estrutura. Sua disposição lembra uma abóboda cilíndrica (abóboda de berço ou semicírculo). No grande edifício, a estrutura se comporta como um único elemento viga/pilar, gerando a sensação, ao entrar no edifício, das paredes de vedação ser um prolongamento da cobertura, ainda que tal sentido seja facilitado pela utilização do mesmo material para vedar e cobrir o edifício, neste caso telhas metálicas.

Por fim, trata-se de um galpão com dimensões grandiosas, $30 \mathrm{~m}$ de largura $\times 115 \mathrm{~m}$ de comprimento $\times 16 \mathrm{~m}$ de altura, sendo considerada uma das maiores construções em madeira do Brasil (Figura 2). A estrutura é formada por 22 pórticos triarticulados treliçados, com predominância de ligações por cavilhas, portanto, não utiliza pregos ou parafusos.

\subsection{MANIFESTAÇÕES PATOLÓGICAS NO SISTEMA ESTRUTURAL DO EDIFÍCIO IBC}

As manifestações patológicas identificadas nas estruturas do IBC estão atribuídas aos agentes bióticos e abióticos, conforme o Quadro 1. Apresenta-se na sequência a Figura 3 , que visa contextualizar as anomalias encontradas nos pórticos treliçados. A Tabela 1 apresenta o número de manifestações patológicas observadas nos elementos estruturais do edifício. Por fim, o Quadro 2 apresenta o registro de algumas das anomalias visualizadas.

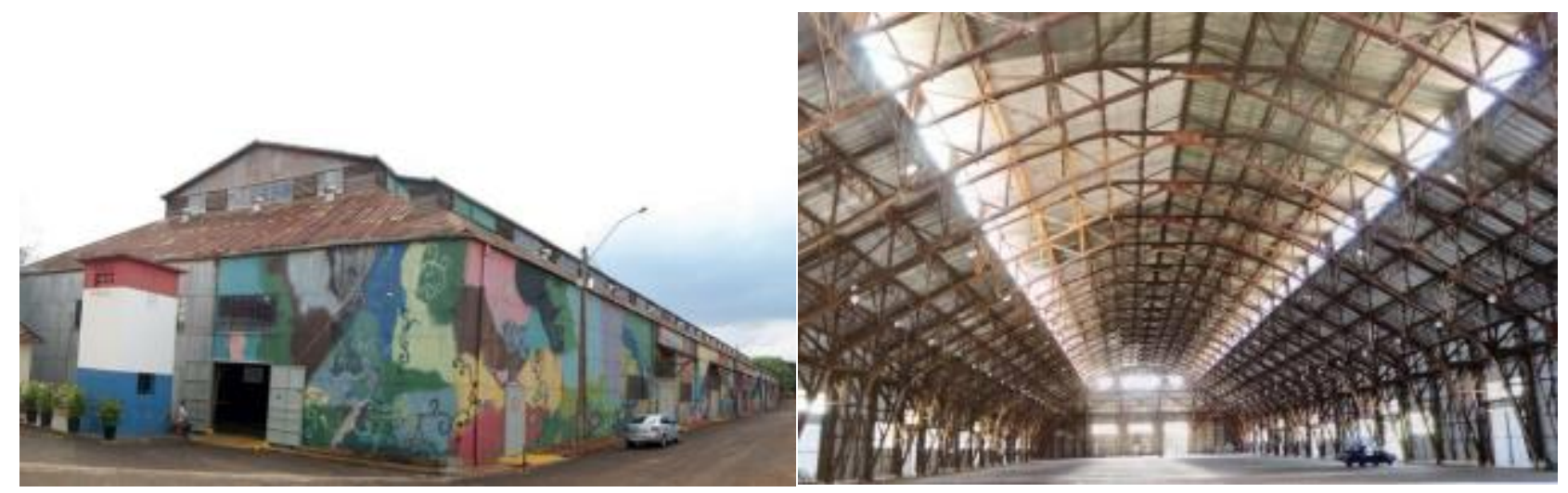

FIGURA 2: Imagem externa e interna do IBC, Presidente Prudente. FONTE: Autoria Própria. 


\section{QUADRO 1: Agentes bióticos e abióticos que estão presentes nas estruturas do IBC.}

Agentes bióticos (vivos)

Os agentes bióticos (vivos) são principalmente os fungos e insetos. Estes organismos necessitam de algumas condições para sua sobrevivência, entre elas: temperatura, oxigênio, umidade e fonte adequada de alimento, geralmente a madeira. Embora o grau de dependência destes parâmetros seja variável, cada um precisa estar presente para ocorrer a deterioração.

Agentes abióticos (não vivos)
Os agentes abióticos (não vivos) incluem os condicionantes físicos, mecânicos, químicos e climáticos. Embora destrutivos, os agentes abióticos podem também danificar o tratamento preservativo, expondo a madeira não tratada ao ataque de agentes bióticos.

FONTE: Autoria Própria.

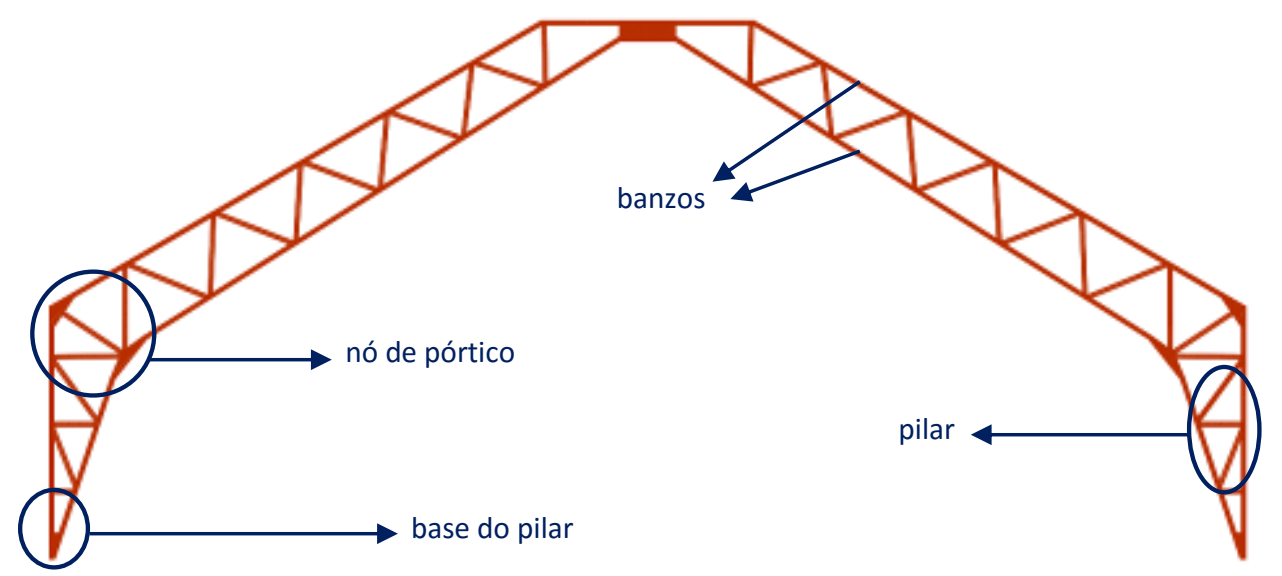

FIGURA 3: Modelo do pórtico treliçado com destaque para as regiões em que grande parte das anomalias foram identificadas nas estruturas do IBC.

FONTE: Autoria Própria.

\section{TABELA 1: Número de manifestações patológicas observadas nas estruturas do IBC.}

\begin{tabular}{|c|c|c|c|c|c|c|}
\hline Elemento & Podridão & $\begin{array}{l}\text { Agentes } \\
\text { bióticos }\end{array}$ & $\begin{array}{l}\text { Irregularidades } \\
\text { geométricas }\end{array}$ & $\begin{array}{c}\text { Uniões deficientes } \\
\text { em cavilhas }\end{array}$ & $\begin{array}{c}\text { Reparos } \\
\text { deficientes }\end{array}$ & Fissuras \\
\hline Base de pilar & 5 & 18 & 4 & 11 & 0 & 7 \\
\hline Pilar & 8 & 22 & 9 & 6 & 0 & 11 \\
\hline Nó de pórtico & 8 & 21 & 0 & 19 & 0 & 3 \\
\hline Viga & 9 & 18 & 12 & 0 & 3 & 0 \\
\hline Total & 30 & 79 & 25 & 36 & 3 & 21 \\
\hline
\end{tabular}

\section{QUADRO 2: Registro de algumas das manifestações patológicas identificadas no IBC.}

Podridão da madeira em base de pilares distintos
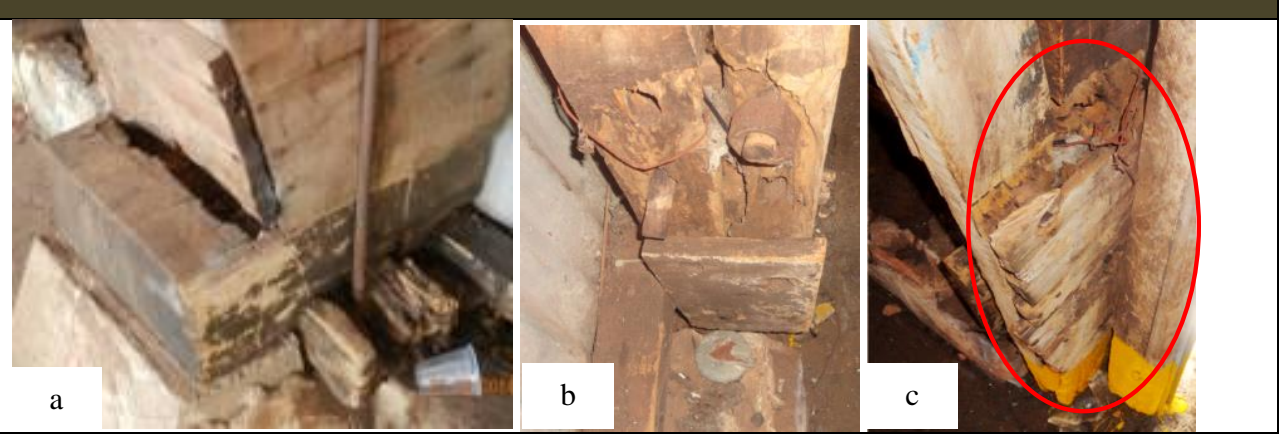

Continua. 
QUADRO 2: Registro de algumas das manifestações patológicas identificadas no IBC (Continuação).

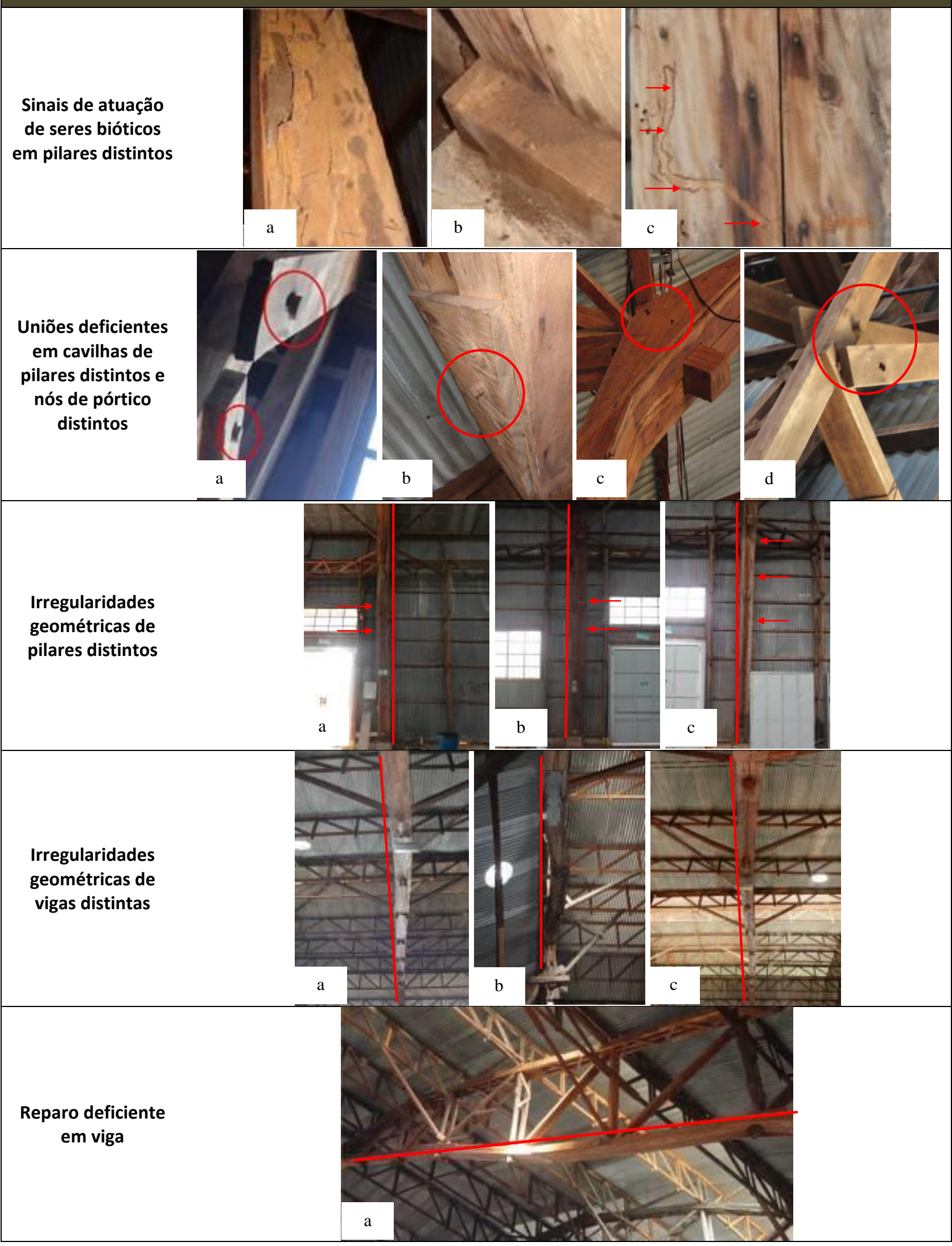


QUADRO 2: Registro de algumas das manifestações patológicas identificadas no IBC (Continuação).

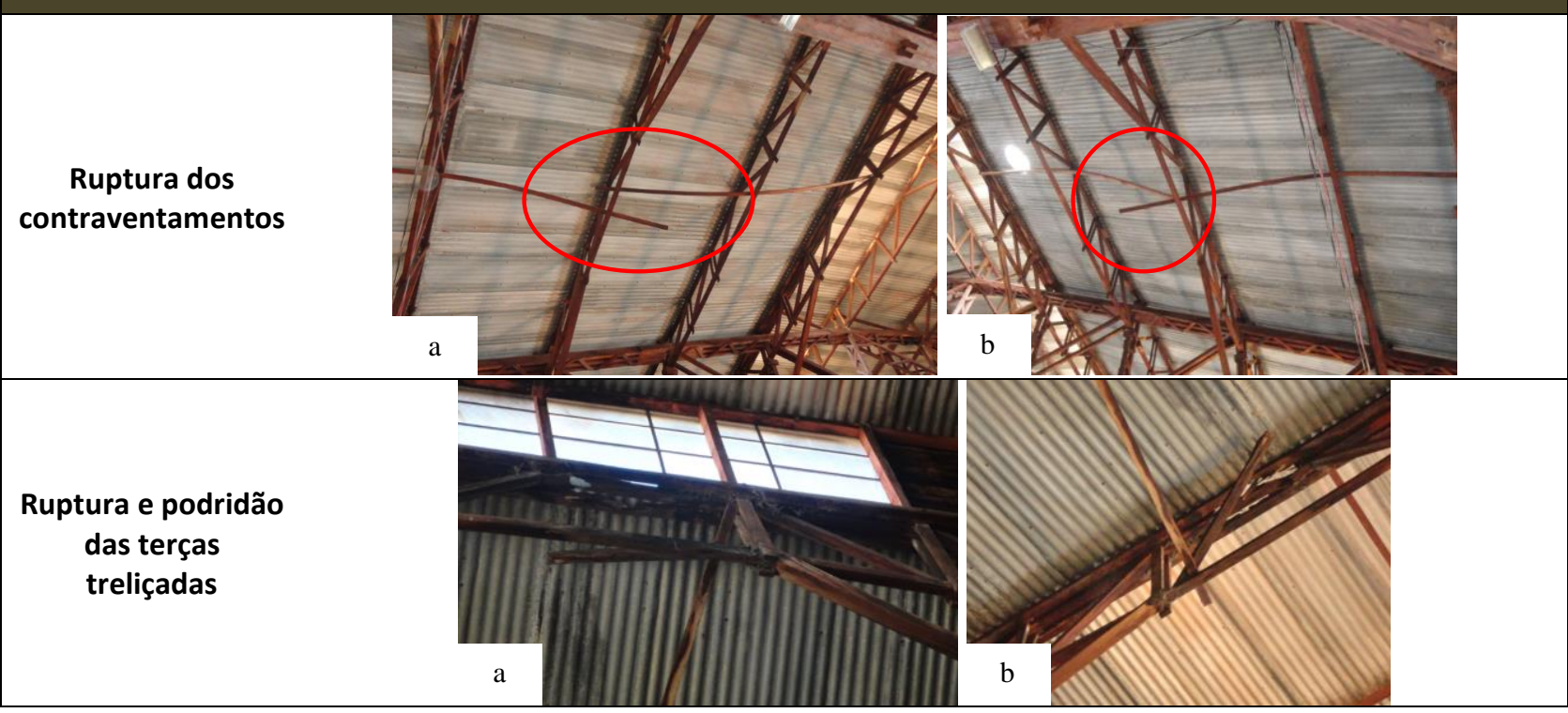

FONTE: Autoria Própria.

\subsection{ASPECTOS GERAIS, CAUSAS PROVÁVEIS E POSSÍVEIS SOLUÇÕES DE REPAROS}

Pôde-se relacionar o levantamento dos aspectos gerais, das causas prováveis e as possíveis soluções de reparo (Quadro 3) a partir dos dados de campo e do registro fotográfico realizado.

QUADRO 3: Aspectos gerais, causas prováveis e possíveis soluções de reparo das manifestações patológicas identificadas no IBC.

\begin{tabular}{|c|c|c|c|}
\hline & Aspectos gerais & Causas prováveis & Possíveis soluções de reparo \\
\hline 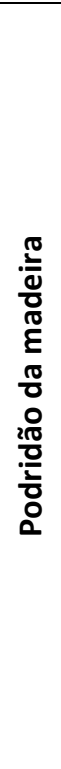 & $\begin{array}{l}\text {-Perda de massa; } \\
\text {-Alteração da coloração e da } \\
\text { textura da madeira; } \\
\text {-Envelhecimento das peças } \\
\text { afetadas; } \\
\text {-Diminuição da resistência, } \\
\text { podendo chegar a destruição; } \\
\text {-Amolecimento das peças } \\
\text { afetadas; } \\
\text {-Porção do material na iminência } \\
\text { de se desprender do todo; } \\
\text { - Descontinuidade do material; } \\
\text { - Prejuízo das questões estéticas; } \\
\text { - Gera desconforto visual aos } \\
\text { usuários. }\end{array}$ & $\begin{array}{l}\text { - Alta umidade relativa no local; } \\
\text { - Infiltração de água de chuva nas } \\
\text { telhas metálicas da cobertura e do } \\
\text { revestimento; } \\
\text { - Umidade ascendente do piso de } \\
\text { concreto; } \\
\text { - Ventilação deficiente no local; } \\
\text { - Falta de manutenção preventiva. }\end{array}$ & $\begin{array}{l}\text { - Remover a madeira podre de dentro } \\
\text { e ao redor dos locais afetados com o } \\
\text { uso de espátulas; } \\
\text { - Lixamento da madeira que } \\
\text { permanece em bom estado após a } \\
\text { retirada da parte com podridão, } \\
\text { limpeza e secagem dessa peça; } \\
\text {-Em caso da área afetada pela } \\
\text { podridão ser pequena em comparação } \\
\text { com o total do elemento, pode-se } \\
\text { aplicar resina epóxi nas áreas afetadas, } \\
\text { obstruindo as cavidades formadas; } \\
\text {-Aplicação de selantes e outros } \\
\text { produtos para a manutenção da } \\
\text { madeira, evitando a umidade; } \\
\text {-Em casos mais avançados de } \\
\text { podridão a peça deve ser substituída } \\
\text { totalmente, ou então a área que } \\
\text { apresenta grandes danos. }\end{array}$ \\
\hline
\end{tabular}

Continua. 
QUADRO 3: Aspectos gerais, causas prováveis e possíveis soluções de reparo das manifestações patológicas identificadas no IBC (Continuação).

\begin{tabular}{|c|c|c|c|}
\hline 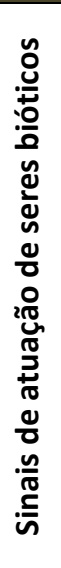 & $\begin{array}{l}\text { - “Caminhos” projetados pela } \\
\text { atuação dos insetos nas peças de } \\
\text { madeira; } \\
\text {-Perda de massa; } \\
\text {-Diminuição de resistência, } \\
\text { podendo chegar a destruição; } \\
\text {-Acúmulo de pó de madeira em } \\
\text { alguns pontos das peças afetadas; } \\
\text {-Perfurações nas peças afetadas; } \\
\text {-Debilitação da madeira frente a } \\
\text { outros ataques; } \\
\text {-Alteração da coloração e da } \\
\text { textura da madeira; } \\
\text {-Prejuízo das questões estéticas. }\end{array}$ & $\begin{array}{l}\text {-Ausência de aplicação de métodos } \\
\text { preventivos na estrutura; } \\
\text { - Temperatura e condições ideais } \\
\text { para a infecção de insetos; } \\
\text { - Alta umidade relativa no local; } \\
\text { - Infiltração de água de chuva nas } \\
\text { telhas metálicas da cobertura e do } \\
\text { revestimento; } \\
\text { - Umidade ascendente do piso de } \\
\text { concreto; } \\
\text { - Ventilação deficiente no local; } \\
\text { - Falta de manutenção preventiva. }\end{array}$ & $\begin{array}{l}\text { - Procurar e identificar inicialmente } \\
\text { qual o ser biótico causador da } \\
\text { manifestação patológica; } \\
\text { - Aplicar o inseticida/bactericida } \\
\text { correto para erradicar a presença do } \\
\text { ser causador da anomalia, sendo mais } \\
\text { comum o uso de produtos químicos } \\
\text { pulverizantes; } \\
\text { - Substituir ou reparar (quando } \\
\text { possível) os elementos em madeira } \\
\text { que foram danificados; } \\
\text { - Aplicar produtos preventivos contra o } \\
\text { surgimento de novos seres bióticos; } \\
\text {-Aplicar selantes de resina epóxi. }\end{array}$ \\
\hline 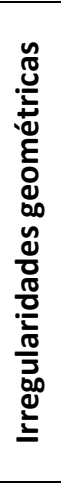 & $\begin{array}{l}\text { - Falta de linearidade das peças; } \\
\text {-Deformação excessiva } \\
\text { visualmente perceptível; } \\
\text {-Prejuízo das questões estéticas; } \\
\text { - Gera desconforto visual aos } \\
\text { usuários. }\end{array}$ & $\begin{array}{l}\text { - Deslocamentos excessivos laterais, } \\
\text { causado por danos, corte ou falta de } \\
\text { barras de contraventamento; } \\
\text { - Ações horizontais superiores as } \\
\text { previstas no cálculo estrutural; } \\
\text {-Efeito da secagem das peças } \\
\text { aplicadas na condição verde; } \\
\text { - Excessivo carregamento que } \\
\text { necessita ser corrigido; } \\
\text { - Falta de manutenção preventiva. }\end{array}$ & $\begin{array}{l}\text { - Por se tratar de uma anomalia que } \\
\text { pode decorrer de falhas no projeto, na } \\
\text { fabricação ou ainda na } \\
\text { execução/montagem, a principal } \\
\text { atenção deveria ser tomada nestas } \\
\text { etapas, mais especificamente na } \\
\text { preocupação com posicionamento dos } \\
\text { elementos e como a junção entre eles } \\
\text { será executada, além da preocupação } \\
\text { com o uso de mão de obra qualificada; } \\
\text {-Introdução de contraventamentos em } \\
\text { pontos que se fazem necessários. }\end{array}$ \\
\hline 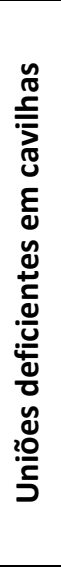 & $\begin{array}{l}\text { - Cavilhas com parte exposta, da } \\
\text { ordem de } \pm 3 \mathrm{~cm} \text {; } \\
\text {-Ausência de cavilhas em alguns } \\
\text { pontos; } \\
\text {-Prejuízo das questões estéticas. }\end{array}$ & $\begin{array}{l}\text { - Falta de manutenção preventiva; } \\
\text { - Falha no posicionamento do } \\
\text { gabarito dos furos. }\end{array}$ & $\begin{array}{l}\text { - Recolocação das cavilhas nas } \\
\text { cavidades em que estas se fazem } \\
\text { necessárias, com o cuidado de que } \\
\text { estejam com as dimensões corretas } \\
\text { para permanecerem no } \\
\text { posicionamento adequado; } \\
\text { - Promover pressão nas cavilhas que } \\
\text { saltam para fora de suas cavidades a } \\
\text { fim de posicioná-las corretamente } \\
\text { dentro das cavidades; } \\
\text { - Retirar cavilhas que estejam } \\
\text { danificadas, com podridão ou ainda } \\
\text { faltando partes e substituí-las por } \\
\text { cavilhas em boas condições de uso. }\end{array}$ \\
\hline 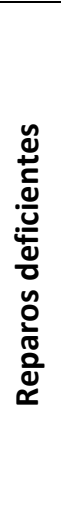 & $\begin{array}{l}\text { - Diferença de coloração das peças } \\
\text { de reparo - espécies distintas de } \\
\text { madeira; } \\
\text {-Deformação que esta } \\
\text { visualmente perceptível; } \\
\text {-Prejuízo das questões estéticas. }\end{array}$ & $\begin{array}{l}\text { Deslocamento ocorrido em função } \\
\text { do efeito da secagem de peças de } \\
\text { reparo aplicadas na condição verde; } \\
\text { - Má execução de reparo - mão de } \\
\text { obra sem qualificação; } \\
\text {-Utilização de espécie de madeira } \\
\text { de reparo com propriedades } \\
\text { mecânicas inferiores as da madeira } \\
\text { original; } \\
\text {-Ausência de projeto de reparo. }\end{array}$ & $\begin{array}{l}\text { - Por se tratar de uma anomalia que } \\
\text { pode decorrer de falhas no projeto, na } \\
\text { fabricação ou ainda na } \\
\text { execução/montagem, a principal } \\
\text { atenção deveria ser tomada nestas } \\
\text { etapas, mais especificamente na } \\
\text { preocupação com posicionamento dos } \\
\text { elementos e como a junção entre eles } \\
\text { será executada, além da preocupação } \\
\text { com o uso de mão de obra qualificada, } \\
\text { fazendo com que, em alguns casos, o } \\
\text { reparo mais indicado é a substituição } \\
\text { e/ou reposicionamento do elemento. }\end{array}$ \\
\hline
\end{tabular}


•Presença de fissuras superficiais direção das fibras da madeira.
J longitudinais que se abrem na

entificadas no IBC (Continuaça). un

\begin{abstract}
- Pode-se aplicar resina epóxi nas áreas afetadas, obstruindo as cavidades formadas;

- Tipicamente é o resultado da -Aplicação de selantes e outros secagem das peças aplicadas na produtos para a manutenção da condição verde;

-Sucessão de ciclos termos-úmidos que incham e encolhem a madeira.

- Dependendo do estado da peça, realizar seu reforço utilizando parafusos, anéis metálicos, chapas metálicas ou adesivos estruturais para fazer a união nas áreas afetadas.
\end{abstract}

FONTE: Autoria Própria.

\section{ANÁLISE}

Devido a motivos históricos, culturais ou artísticos, a conservação de estruturas antigas de madeira está se tornando cada vez mais importante. A preservação da aparência da estrutura está relacionada com a quantidade de degradação dos elementos de madeira e, em certas situações, os elementos estruturais afetados pelo elevado ataque de agentes bióticos ou danos podem ser reforçados a partir de uma correta detecção do problema e agente causador.

Através da vistoria e estudos realizados no IBC foi possível observar que as causas prováveis das manifestações patológicas são distintas e diversas, e partem de fatores variados. Como se sabe, a madeira só atinge a plenitude das suas propriedades quando se encontra no estado normal. Ainda assim, o envelhecimento precoce de muitas estruturas de madeira e a sua consequente perda de prestígio como material estrutural, ocorre, principalmente, devido às interferências de utilização da estrutura realizadas posteriormente à sua construção, que, na maioria das vezes, geram anomalias.

No levantamento realizado, foram detectados problemas relacionados aos ataques bióticos em vários elementos da estrutura, principalmente devido ao fato de que a madeira é um material bastante susceptível a este tipo de ataque, sendo esta uma das manifestações patológicas mais comuns nas estruturas de madeira, e que geram as degradações mais graves, existindo inúmeros agentes de degradação que alteram as suas propriedades como elemento de construção.
Segundo Worrall (2013) para fins práticos, os fungos são os principais agentes apodrecedores da madeira. $O$ autor ainda define que $o$ apodrecimento ou decomposição da madeira é uma biodeterioração da madeira originária por atividades principalmente enzimáticas de microorganismos, e também considera o apodrecimento como o grande vilão entre as causas de deterioração da madeira. Conforme Broto (2005), cada espécie de inseto necessita de condições ambientais particulares, e a maioria deles se desenvolve com umidade da madeira e temperaturas relativamente altas, da ordem de $\mathrm{H}=15 \%$ e $\mathrm{T}=15-30^{\circ} \mathrm{C}$, respectivamente.

Outro tipo de ataque biótico sofrido pela estrutura do IBC foi produzido por insetos que realizam aberturas de galerias ou "tubos" característicos no exterior dos elementos atacados, sendo normalmente detectadas apenas em fases avançadas e pelo volume de madeira depredada, constituindo um problema geralmente grave e frequentemente de difícil resolução, em que a perda de resistência dos elementos de madeira afetados será em função do volume de material consumido. Os elementos que sofrerem esse tipo de dano devem ser reparados a fim de se preservar a resistência dos elementos e as características estruturais necessárias, sendo que inicialmente é importante procurar e identificar qual ser biótico é o causador do problema patológico para então utilizar o produto químico correto para erradicar a presença do agente causador da anomalia, sendo comum o uso de pulverizantes. Em casos mais avançados deve substituir parte ou o todo (quando 
for possível) dos elementos que foram danificados e sempre aplicar produtos preventivos contra 0 surgimento de novos seres bióticos das variadas naturezas.

A podridão - que é facilmente identificada pela perda de peso e consequente redução de resistência da madeira, acompanhada por alterações típicas de coloração e de aspecto - foi detectada em várias das peças que compõem a estrutura do IBC. De acordo com Cruz (2001), uma habitual fonte de manifestação patológicas na madeira reside no contato com água ou teor de umidade ambiente elevado. É importante saber que a umidade, por si só, não degrada a madeira, mas potencializa o risco de deterioração desse material por determinados agentes biológicos, no sentido em que esses só atacam a madeira quando o seu teor de umidade atinge determinados valores. Especificamente, quando a madeira permanece em condições de umidade elevada por períodos longos, favorece o ambiente ao ataque por fungos ou por térmitas subterrâneas que dela se alimentam.

As peças e elementos com esse problema de deterioração necessitam de reparos imediatos a fim de se evitar maiores prejuízos estruturais, tendo como possíveis reparos inicialmente a remoção da madeira podre de dentro e ao redor dos locais afetados com o uso de espátulas e outros materiais do gênero, realizando posteriormente o lixamento da madeira que se manter permissível de uso, bem como sua limpeza e secagem. Em casos onde a área afetada pela podridão for relativamente pequena em comparação com o total do elemento, este pode ser reparado aplicando-se resinas epóxi nas áreas em que houve a perda de material, obstruindo cavidades que foram formadas, lixando o excesso de resina epóxi e aplicando selantes e outros produtos para a manutenção da madeira evitando a ação da umidade novamente, porém, em casos mais avançados de podridão a peça deve ser substituída totalmente ou então somente a área que apresenta grandes danos, nos casos em que esta ação se faça possível.

Com relação aos agentes abióticos, estes são consequência de fenômenos climáticos e meteorológicos como a radiação solar (UV e IR), a umidade ambiental, a chuva e o vento (Broto, 2005).
Trata-se de todos aqueles que não são organismos vivos e que podem causar lesões e danos na madeira: comportamento da madeira frente à água, deformabilidade da madeira, envelhecimento da madeira e o fogo. Diante disso, foi observada a falta de alinhamento no sistema estrutural analisado, sendo que, em muitos dos pórticos do edifício se pode observar um claro desalinhamento das vigas e dos pilares, com um traçado serpenteante.

Outra manifestação patológica percebida foram os reparos deficientes em vigas, que, provavelmente devido à presença de agentes bióticos foram necessários reparos pontuais nas mesmas, ocorrendo a substituição das peças afetadas por outras novas, porém - em função da diferença de coloração - foram utilizadas espécies diferentes de madeira. Os reparos apresentam visíveis deformações, resultado do incorreto reparo, que causam certo desconforto aos usuários do edifício. Para essas anomalias os reparos tornam-se mais complexos e muitas vezes inviáveis, pois, por ser um problema patológico que pode decorrer de erros de projeto, erros na fabricação ou ainda na execução/montagem, a principal atenção deveria ter sido aplicada nestas etapas, pois apresentam nessa fase atual, de utilização, dificuldades para se reparar ou substituir os elementos irregulares que estão em uso, não se aplicando muitas vezes esse tipo de reparo.

Fissuras foram percebidas em algumas peças que compõem os pórticos. Apresentam grande variedade referente a espessura, ainda que muita similaridade na forma, já que a maioria se encontra de maneira longitudinal ao longo da peça afetada. Essas fissuras abrem novas vias de agressão - sobre tudo para fungos e insetos - e permitem que a água penetre com facilidade e circule pelo interior das peças. Segundo Calil Jr. et al (2006), um dos defeitos naturais da madeira são as fissuras, que tipicamente resultam da secagem ao ar livre, quando a madeira é instalada ainda verde in loco.

Segundo Botelho Junior (2006), essa manifestação patológica pode ocorrer devido à alternância de ciclos de umidificação e secagem, acarretando em variação volumétrica do material. Esta variação provoca tensões internas na peça de madeira, resultando deste fenômeno o 
aparecimento de fendas, curvaturas e empenamentos. As fissuras podem ser consideradas uma das causas mais comuns de perda de resistência das peças de madeira. Seus reparos podem ser realizados através da aplicação de resina epóxi nas áreas afetadas, obstruindo as cavidades formadas, bem como o uso de selantes para sua manutenção, e dependendo do estado da peça de madeira pode-se realizar seu reforço.

Por fim, as uniões deficientes em cavilhas também foi uma manifestação patológica identificada em vários pontos da estrutura, em que muitas delas estão com parte exposta para fora dos furos em que foram inseridas, ou ainda, em alguns pontos, notou-se até mesmo a falta deste componente, acarretando em possíveis prejuízos de resistência e de funcionamento da estrutura, pelo fato de que as cavilhas encontram-se nos pontos de ligações entre os elementos que constituem a estrutura como um todo, sendo necessário o seu correto uso e manutenção. Neste aspecto, uma manutenção periódica solucionaria estes problemas e contribuiria no aumento da vida deste galpão.

Diante do exposto, deve ser relatado que as manifestações patológicas analisadas apresentam real importância para o estudo realizado, pois quando somadas acarretam em danos e prejuízos para o sistema estrutural como um todo, afetando o bom funcionamento do edifício estudado.

\section{CONCLUSÕES}

As análises e resultados obtidos foram decorrentes de trabalhos de campo realizados em toda a edificação. Ressalta afirmar que o resultado do levantamento possui grande relevância, pois a partir das informações obtidas e fornecidas com a elaboração deste estudo, pode-se propiciar conhecimento e melhorias nos níveis atuais de durabilidade e vida útil das estruturas de madeira.

O edifício IBC, construído na década de 1940, é um dos mais antigos e conhecidos do município de Presidente Prudente-SP. Seu grande espaço aberto ajudou sua característica polifacética, tendo servido de local de recolhimento de carros apreendidos e atualmente recebe vários tipos de eventos sócio-culturais. No entanto, não sofreu qualquer adaptação ou modificação a qualquer uma dessas mudanças no uso.

Diante disso, as manifestações patológicas identificadas, de maneira geral, foram: podridão, sinais de atuação de seres bióticos, irregularidades geométricas, uniões deficientes em cavilhas, reparos deficientes, e fissuras.

O edifício IBC apresenta manifestações patológicas em diferentes intensidades e nos diferentes elementos estruturais que as compõem (vigas e pilares), acarretando não somente no desconforto visual e prejuízo das questões estéticas, como também em possíveis problemas para o correto funcionamento de seu sistema estrutural.

Os agentes bióticos identificados no edifício IBC foram os fungos e os insetos xilófagos, que são os que produzem mais danos à estrutura de madeira. No entanto, os ataques por agentes abióticos também estão presentes, principalmente pelas constantes variações de umidade e temperatura. Por meio das inspeções realizadas se observou que um lado do edifício é o mais afetado pelas manifestações patológicas, possivelmente porque ele coincide com a direção do vento e da chuva habitual.

Foi possível constatar que o principal fator da existência de tantos problemas detectados devese, predominantemente, à falta de manutenções adequadas as estruturas, que não são realizadas de forma constante e preventiva, contribuindo para o aparecimento das manifestações patológicas, como também para o aumento do grau e intensidade delas, acarretando na necessidade de processos de reparos e reestruturação, afetando o funcionamento da edificação e levando a um gasto financeiro maior do que se houvesse uma prevenção efetiva e constante.

Através deste estudo e das análises realizadas, é possível afirmar que muitas das manifestações patológicas detectadas poderiam ter sido minimizadas, e até mesmo evitadas, caso houvesse maior controle das etapas do processo construtivo, e que ao serem associadas a uma efetiva manutenção das estruturas de concreto armado, poderiam proporcionar maior qualidade e vida útil aos elementos estruturais. 
Por fim, este trabalho contribui como forma de exemplificar as possíveis manifestações patológicas que ocorrem em elementos construtivos em madeira, bem como suas causas prováveis e possíveis soluções, servindo de alerta para projetistas, construtores e usuários, os problemas patológicos que podem ocorrer em estruturas de madeira quando estas não recebem os cuidados e procedimentos necessários para seu funcionamento ideal e, com isso, proporcionar maior atenção e consciência por parte desses, a fim de que se atentem cada vez mais para as precauções e especificações de procedimentos a serem tomadas para a construção, como também para a utilização de uma estrutura deste material.

\section{AGRADECIMENTO}

À FAPESP - Fundação de Amparo a Pesquisa do Estado de São Paulo, pela concessão das bolsas de iniciação científica (IC) e estágio de pesquisa no exterior (BEPE) a autora, durante o período de agosto de 2013 a janeiro de 2016.

\section{REFERÊNCIAS BIBLIOGRÁFICAS}

BOTELHO JUNIOR, J. A. Avaliação não destrutiva da capacidade resistente de estruturas de madeira de edifícios antigos. Dissertação (Mestrado em Reabilitação do Patrimônio Edificado) - Faculdade de Engenharia da Universidade do Porto, Porto, Portugal, 2006, 208p.

BRITO, L. D.; CALIL JR, C. Nondestructive assessments of the timber roof structure of the 'São Francisco Church' in Florianopolis, Brazil. In: 18th International Nondestructive Testing and Evaluation of Wood Symposium. Madison, 2013.

BRITO, L. D. Patologia em estruturas de madeira: Metodologia de inspeção e técnicas de reabilitação. Tese apresentada ao Departamento de Engenharia e Estruturas da Escola de Engenharia de São Carlos da Universidade de São Paulo. 2014.

BROTO, C. Enciclopedia Broto patologías de la construcción. Barcelona: Links Internacional, 2005. 1396 p. Disponível em: <http://higieneyseguridadlaboralcvs.files.wordpress.co m/2012/07/enciclopedia_broto_de_patologias_de_la_c onstruccion.pdf $>$. Acesso em: 22 de setembro de 2014.
CAMPOS, J. A. O.; OLIVEIRA, F. G. R.; SALES, A. Avaliação da durabilidade de uma passarela pênsil em madeira. VIII EBRAMEM, Uberlândia, 2002.

CRUZ, H. Patologia, avaliação e conservação de estruturas de madeira. II Curso Livre Internacional de Patrimônio - Associação Portuguesa dos Municípios com Centro Histórico: Fórum UNESCO Portugal. Santarém, 2001, 9p.

KLIMPEL, E. C.; SANTOS, P. R. C. Levantamento das manifestações patológicas presentes em unidades do conjunto habitacional Moradias Monteiro Lobato. Trabalho de Conclusão de Curso (Especialista em Patologia nas Obras Civis) - Instituto IDD, Curitiba, 2010, $98 p$.

MACEDO, R. IBC: muito além de um barracão antigo. Casa Vitrine, 2013, ano 5, edição 7, pp. 314-316.

MAIDEL, B. et al. Patologias das edificações. Centro Tecnológico - Faculdade de Arquitetura e Urbanismo Universidade Federal de Santa Catarina, Florianópolis, 2009, 68p.

RODRIGUES, M. A. S.; J. C. SALES. A madeira e suas patologias. Estudo de caso: Igreja Nossa Senhora das Mercês - Itapipoca/CE. In: IX Congreso Internacional sobre Patología y Recuperación de Estructuras. João Pessoa-PB (Brasil), 2013.

SOUZA, V. C. M. de.; RIPPER, T. Patologia, recuperação e reforço de estruturas de concreto. São Paulo: PINI, 1998, $255 p$

ZENID, G. J. Madeiras para móveis e construção civil. São Paulo: IPT/SCTDE, 2002. CD-ROM (IPT - Publicação, 2779).

WORRALL, J. J. (2013). Wood Decay. Forest and Shade Tree Pathology. USDA Forest Service, Rocky Mountain Region. Forest Health Management. Colorado St. Disponível em: <http://www.forestpathology.org/dis_decay.html\#term s> Acesso em 05/05/2016. 